\title{
Imagem Pública Política: o Último Populismo de Chávez
}

\author{
Public Political Image: the Last Populism of Chavez
}

\author{
Érica Anita Baptista \\ Mariana Rezende dos Passos
}

\section{Resumo}

O populismo é uma importante marca na política latino-americana e a emergência de líderes considerados neopopulistas, como o ex-presidente da Venezuela, Hugo Chávez, está entrelaçada às mudanças na percepção sobre política pelos cidadãos. O presente artigo busca compreender, portanto, como se deu a construção da imagem pública política de Hugo Chávez para que o conceito de neopopulismo fosse atribuído ao governo chavista. O período analisado compreende a eleição presidencial de 2012 na Venezuela. Nossas hipóteses iniciais, confirmadas pela análise, indicavam, principalmente, a existência de uma ênfase estratégica no populismo de Chávez na eleição de 2012 e, ainda, sinalizavam não apenas a existência do voto personalista, mas também a opção do voto retrospectivo em Chávez.

\section{Palavras-chave}

Populismo; Imagem Pública Política; Hugo Chávez; Venezuela.

\begin{abstract}
Populism is a major brand in Latin American politics and the emergence of so called populist leaders, such as the former president of Venezuela, Hugo Chavez, is interwoven with changes in the perception of politics by citizens. This paper seeks to understand, therefore, the construction of Hugo Chavez public political image so the concept of neo-populism could be attributed to Chavez's government. The period analyzed was the 2012 presidential election in Venezuela. Our initial hypothesis, confirmed by the analysis, indicated the existence of a strategic emphasis Chavez populism in the 2012 election and also signaled not only the existence of personality-centred voting, but also the option of retrospective vote for Chavez.
\end{abstract}

\section{Keywords}

Populism; Public and Political Image; Hugo Chávez; Venezuela. 


\section{Introdução}

Durante a década de 1990, a América Latina passava por um processo de desencanto político e econômico com as reformas neoliberais. Garretón (2007) destaca que, naquele momento, ainda era preciso vencer alguns desafios. $\mathrm{O}$ autor enumera quatro deles, sendo que o primeiro consistia na construção de sistemas políticos democráticos. O segundo, e não menos importante, se tratava da necessidade de estabelecer uma democratização social, capaz de reduzir a pobreza e as desigualdades sociais e, também, promover a participação dos cidadáos. $\mathrm{O}$ terceiro mostra a necessidade de reformulação do modelo econômico implantado com as reformas estruturais do chamado "Conselho de Washington" para que se pudesse (re)estruturar um Estado de bem-estar. Por fim, a necessidade de construção de um modelo de modernidade que permitira a inserção dos diferentes países de forma autônoma em processos de globalização, uma vez que seriam incorporadas as diversidades culturais dos países e regiōes.

Os regimes que se instauraram no período pós-ditatorial na América Latina, no entanto, se consolidaram, ainda que nem todos sejam genuinamente democráticos (GARRETÓN, 2007). No plano econômico e social, é importante lembrar que, em muitas regióes da América Latina, pouco se avançou em termos de superação da pobreza e crescimento econômico dos países. Quanto aos processos políticos, Garretón (2007) salienta que é importante pensar no "avanço da esquerda" e no neopopulismo, e, também, considerar o contexto em que se inserem.

O populismo também se faz presente nos processos eleitorais, sobretudo, nas campanhas políticas. E as eleições na América Latina podem ser analisadas a partir de vários aspectos, os quais Figueiredo e Aldé (2003) destacam dois segmentos. Em uma abordagem, têm-se as chamadas variáveis estruturais: a identificação partidária e ideológica dos eleitores; o posicionamento de classe; a avaliação do estado da nação; avaliação do desempenho dos governantes; e a avaliação da situação econômica. Em outro caminho, encontram-se as variáveis comunicacionais, sendo que algumas são classificadas como estáveis ao longo do tempo, por exemplo, os hábitos de consumo e a exposição à mídia, e aquelas avaliadas como de "curtíssimo prazo", que seria a exposição às propagandas políticas, de modo geral, e também em momentos eleitorais (FIGUEIREDO, 1991; FIGUEIREDO e ALDÉ, 2003).

Também é relevante à proposta aqui apresentada, retomar as teorias que buscam compreender o comportamento eleitoral e, dentre elas, pode-se destacar três correntes de estudos: sociológica, psicológica e a teoria da escolha racional.

No modelo proposto pela corrente sociológica, adota-se uma perspectiva macro da análise e os grupos sociais têm grande importância nas escolhas dos 
indivíduos. As relações interpessoais que ocorrem dentro desses grupos condicionam as preferências políticas, ou seja, os indivíduos formam suas atitudes e reforçam suas preferências em função das relações que estabelecem no interior dos grupos sociais (LAZARSFELD, BERELSON e GAUDET, 1965). A corrente psicológica, da Escola de Michigan, se valendo e admitindo a importância de elementos macroestruturais tratados na corrente sociológica, traz como foco o indivíduo e suas motivações psicológicas ocupam posição central e não apenas os grupos sociais. A identificação partidária é central aos estudos de Michigan e diz respeito a uma relação afetiva que os eleitores mantêm com os partidos políticos; a identificaçáo seria um filtro perceptivo, por meio do qual os eleitores consideram aspectos que são favoráveis à orientação do partido e rejeitam o que for contrário a essa orientação (CAMPBELL et al., 1960).

A corrente de estudos conhecida como Teoria da Escolha Racional parte de uma perspectiva economicista, em que as identidades culturais não são consideradas condicionantes do comportamento político e as características individuais são postas em relevo (DOWNS, 1957). De acordo com essa vertente de estudos, os indivíduos são racionais e o objetivo final é sempre maximizar os seus ganhos. Os eleitores não teriam interesse em dispender muito esforço na obtenção de informações e para isso recorreriam aos chamados atalhos informacionais para auxiliar na tomada de decisão.

A partir dos conceitos apresentados, nossa proposta é observar a construção da imagem pública política de Hugo Chávez em direção ao populismo, em suas estratégias de campanha eleitoral em 2012. As hipóteses iniciais sinalizam para a existência da ênfase estratégica no populismo de Chávez. Do ponto de vista do comportamento eleitoral, estudos recentes sinalizam para explicações no voto retrospectivo (BAQUERO e LINHARES, 2011), em recompensa a um bom governo, e ao voto multiclasse (LUPU, 2010), pela mobilização não apenas das classes mais baixas, mas de parcelas da classe média.

\section{O cenário político latino-americano: antecedentes}

Para compreender aspectos da política venezuelana, é relevante fazer um breve relato sobre o passado recente da política na América Latina. A década de 1970 é importante para a regiáo, na medida em que marca as primeiras experiências inspiradas por um modelo político-econômico liberal-liberal conservador (Reagan nos EUA e Thatcher na Grã-Bretanha), sobretudo na Argentina, Chile e Uruguai (MÄDER, 2007). Projetos de caráter nacional-popular ou desenvolvimentistas, que dominaram a agenda política na América Latina desde a década de 1930, foram abandonados e adotado um programa de políticas e reformas liberais. Porém, esse 
modelo econômico, com o passar do tempo, não sustentou sua promessa de crescimento econômico, redução de desigualdades sociais e de pobreza. Como argumenta Mäder (2007), as vitórias eleitorais de novas lideranças políticas com propostas inovadoras podem ser justificadas por um sentimento de frustraçáo criado na década de 1990 pelas políticas neoliberais.

Considera-se que houve uma renovação política na América Latina nos últimos anos, o que, para autores como Cheresky (2007), tem aspectos importantes como a expansão da presença do cidadáo na vida pública e a emergência de novos líderes.

Algumas razóes podem indicar o enfraquecimento dos partidos como um elemento que favorece o surgimento de novos líderes e personalizando a política, como a aparente verticalidade no processo de tomada de decisóes partidárias e as denúncias de posicionamentos oligárquicos dos partidos. Dentre os problemas dos partidos latino-americanos, a rejeição da população é relevante (SAÉZ e FREIDENBERG, 2002). Porém, destaca-se que os partidos ainda continuam estruturando a competição eleitoral e dando forma aos resultados.

Baquero (1998), ao retomar Wanderley G. dos Santos (1985), destaca que a situação que se verifica no Brasil, situação esta que pode ser aplicada à América Latina como um todo, é um distanciamento crescente entre o governo e a sociedade política estruturada. Ao mesmo tempo, observa-se "a multiplicação rápida de novas fontes de geração de identidades coletivas que escapam ao controle do oligopólio partidário" (SANTOS, 1985 apud Baquero, 1998, p. 51). O individualismo que fragmenta as identidades coletivas é considerado um fator para esse distanciamento, o que favoreceria o sentimento de rejeição aos partidos.

No início dos processos de transição democrática (1978-1980), a América Latina contava com quatro cenários distintos: a) países com tradiçóes partidárias sólidas: Argentina, Chile e Uruguai; b) um modelo misto, com partidos antigos e novos, surgidos do processo de transição, que mantinham uma estrutura sólida e em torno dos quais o novo sistema político democrático ainda girava, como o Movimento Nacionalista Revolucionário (MNR da Bolívia) e o Partido dos Trabalhadores (PT - Brasil); c) casos definidos pela manutenção da existência de organizações, porém historicamente vazias do ponto de vista político e social Paraguai; d) países em que não havia um marco mínimo de partidos, somando, ainda, a debilidade histórica partidária aos efeitos dos últimos tempos dos governos autoritários: El Salvador, Guatemala, Nicarágua e República Dominicana (SAÉZ e FREIDENBERG, 2002). 
Dos 20 países da América Latina apenas o Haiti não é presidencialista, sendo regido pelo sistema semi-presidencialista. Vale dizer também que Cuba se declara socialista e a Venezuela, bolivariana (inspirada nos ideais de Simón Bolívar). Sobre os mandatos e as eleiçóes presidenciais cabe mencionar que o mandato varia entre quatro e seis anos, e as eleições se realizam pelo voto direto e secreto (em Cuba, as eleições são indiretas e o mandato não tem período legalmente definido).

A respeito da possibilidade de reeleição do presidente, Saisi (2011) resume a situação nos países latinos no quadro abaixo. É importante destacar que a possibilidade de reeleição favorece o continuísmo e também caminha na direção contrária da alternância de poder.

Quadro 1 - Possibilidade de reeleição presidencial

\begin{tabular}{|c|c|c|c|}
\hline $\begin{array}{c}\text { Náo permite reeleiçáo } \\
\text { em nenhuma hipótese }\end{array}$ & $\begin{array}{c}\text { Permite reeleição apenas após } \\
\text { intervalo }\end{array}$ & $\begin{array}{c}\text { Permite reeleiçáo } \\
\text { imediata }\end{array}$ & $\begin{array}{c}\text { Permite reeleição } \\
\text { indefinida }\end{array}$ \\
\hline Costa Rica Guatemala & $\begin{array}{c}\text { Bolívia } \\
\text { Chile }\end{array}$ & Argentina & \\
Honduras & El Salvador & Brasil & \\
México & Haiti & Colômbia Equador & Cuba \\
Paraguai & Nicarágua & Peru & \\
& Panamá & Venezuela* & \\
& República Dominicana & & \\
& Uruguai & \\
\hline
\end{tabular}

*Na Venezuela, além de ser permitida a reeleição imediata, não há restrições às reeleições consecutivas desde 2009.

Fonte: Quadro elaborado a partir de Saisi (2011).

Sobre o sistema eleitoral, retoma-se o trabalho de Saisi (2011) que conclui que o sistema de eleição predominante hoje na América Latina é aquele que admite a eleição por maioria absoluta e com a possibilidade de segundo turno entre os dois mais votados. A autora ainda destaca que, no final da década de 1980 , a situação era diferente na maioria dos países e bastava haver maioria relativa.

$\mathrm{Na}$ Venezuela, o sistema de partidos, tradicionalmente estável e consolidado, desde o início da democracia (1958), a partir do ano de 1993, passou por várias crises, transformando sensivelmente a sua constituição.

A deslegitimação e desinstitucionalização dos partidos tradicionais, a crise na militância, o crescente personalismo, reunido à transformação do sistema eleitoral, prolongaram a instabilidade ao impedir a institucionalização de novas formas de relação dos partidos com a sociedade (BRICEÑO, 2013, p. 301). 
Quanto às preferências partidárias na Venezuela, Briceño (2013) destaca que a concentração se dá em torno dos partidos tradicionais, Ação Democrática (AD) e Comitê de Organização Política Eleitoral Independente (COPEI- Partido Social Cristão, por suas raízes sociais que se observam mesmo antes da democracia, em 1958).

O cenário que se verifica entre 1958 e 1973 é de multipartidarismo, porém a concentração dos votos era saliente. O que resultou em um sistema bipartidário, entre 1973 e 1993. A partir das eleiçôes regionais e locais de 1989, sobretudo, a partir da eleição presidencial de 1993, a deslegitimação dos partidos e do sistema político verificou-se um processo de fragmentação partidária, que se mantém nos dias atuais. Briceño (2013) pontua que no processo de desinstitucionalização do sistema de partidos da Venezuela, a liderança de Chávez surgiu como uma alternativa a partir de 1998. E os anos seguintes caracterizaram-se por um "abandono" da política pelas elites venezuelanas e maior estímulo para a política por parte das classes populares, completa o autor.

\section{Personalismo: o populismo e o populista}

O personalismo é uma característica importante na América Latina, sobretudo em países como o Brasil (TELLES, 2012; BAQUERO, 1998). O personalismo político, em sua forma tradicional, vem sendo suplantado em muitos casos pelo "neo-populismo", em que a liderança seria uma espécie de evolução histórica da própria cultura política, na qual se percebe significativa aceitação a líderes personalistas e populistas (BAQUERO, 1998). Há uma vasta discussão e variadas divergências quanto ao uso do termo populismo e sua recente derivação, o neopopulismo (WEFFORT, 2003; MÄDER, 2007).

Os primeiros registros de estudos acerca do populismo são da década de 1950, com Gino Germani (1981). No entanto, não se pode dizer da existência de conceitos precisos, o que permite encontrar referências tanto de um movimento político, quanto de uma ideologia (LACLAU, 1980).

Segundo Mitre (2008), o termo populismo carrega uma longa história que se deu de início com os ideais socialistas do século XIX, especificamente na Rússia, com a tentativa de implantaçáo de uma democracia camponesa. Já no século $\mathrm{XX}$, o populismo foi utilizado para designar as revoltas de origem rural na América do Norte. Essas revoltas não eram idealizadas especificamente pelo socialismo, mas caracterizavam um descontentamento do povo em relaçáo ao avanço do grande capital agrícola. O termo populismo ganhou força na América Latina a partir da fase nacional desenvolvimentista e caracterizava determinados tipos de governos. 
Para Villas (2003) e Mitre (2008) o populismo clássico latino-americano, característico do período entre as décadas de 1930 a 1960, apresenta peculiaridades em relaçáo aos outros movimentos também considerados populistas. A principal diferença é o caráter urbano e modernizador. Villas (2003) cita outras características importantes:

[...] uma ampla mobilização social; a integração das classes populares principalmente, mas não exclusivamente, urbanas em um esquema de articulaçẫo política multiclassista; a promoção de uma maior diferenciação econômica capitalista com ênfase na industrialização, impulsionada por um Estado intervencionista dentro de uma estratégia econômica mista e do alinhamento internacional; ressonâncias ideológicas nacionalistas; com uma condução fortemente personalista (VILLAS, 2003, p.14).

Ainda para Villas (2003), tratou-se de uma resposta a um determinado momento do capitalismo que tinha como principais objetivos a melhor distribuição de renda e a promoção do mercado interno. Os governos desta época que bem caracterizavam o populismo foram o de Getúlio Vargas no Brasil (varguismo), e de Perón, na Argentina (peronismo). Outra característica importante do populismo clássico latino-americano é a reconfiguração da sociedade por meio da ascensão das classes mais populares e da relação líder/massa, através dos sindicatos, comitês, e organizaçóes, que proporcionou a essas classes, desempenhar um papel político e social inédito.

Para Mitre (2008) é a partir da década de 1980, marcada pelo início da orientação neoliberal, que surgem as primeiras tentativas de desvincular o populismo de sua referência à fase nacional desenvolvimentista. $\mathrm{O}$ fenômeno populista passou a ser caracterizado como um "vírus", uma doença crônica de partidos majoritariamente de esquerda. Esses governos passavam a adotar medidas macroeconômicas que estimulavam os gastos públicos e os salários com intenção de fazer crescer suas economias de forma rápida. Eram bastante criticados pelas teorias da boa economia por não escolherem medidas que tenderiam a aumentar gradualmente a produtividade.

É a partir dessa fase que surge a hipótese do neopopulismo.

Uma vez que o populismo [...] assumiu a condição de síndrome sem relação com o sistema social, e sua causa passou a se alojar no temperamento afoito de algumas lideranças, ficou expedito o "caminho para a formulação da hipótese neoliberalista” (MITRE, 2008, p. 12). 
Surgiram, então, alguns traços que pontuavam e agrupavam certos regimes na hipótese neopopulista, tais como políticas clientelistas, personalismo e políticas assistencialistas. O termo populista, segundo Mitre (2008), se converte, nesse momento, em um "adjetivo sem coloração ideológica" e passa a ser aplicado a governos de esquerda ou de direita.

De todo modo, estudos recentes concordam que, guardadas as diferenças, o populismo e o neopopulismo possuem dois importantes elementos em comum: personalismo e autoritarismo. Assim como o seu parente clássico, o neopopulismo não se aproxima dos mecanismos democráticos, ignora os canais que possibilitam negociações e traz métodos autocráticos (WAISBORD, 2013; TORRE, 1992).

Villas (2003) esclarece que para alguns estudiosos o populismo é apenas um discurso político (reducionismo discursivo), já para alguns economistas o populismo é um conjunto de políticas monetárias e de gasto público (reducionismo econômico) o que, para Vilas (2003), é um desconhecimento de que esta prática não é exclusiva do populismo e não foi utilizada por todos os regimes populistas. Ainda para o autor, essas concepçóes reducionistas do populismo que abriram caminho para a formulação do neopopulismo faz desse novo termo um pastiche conceitual do populismo.

O populismo, segundo Carneiro (2009), é pensado, basicamente, sob dois aspectos: econômico e político. Do ponto de vista econômico, o populismo é definido, de acordo com a autora, quando se tem um cenário de indisciplina fiscal e de expansão das políticas redistributivas em resposta a pressão da população. No entanto, a literatura mostra que esse viés relaciona-se a uma conjuntura específica, entre as décadas de 1930 e 1970, quando as restrições fiscais não se mostravam tão severas se comparadas às do contexto atual, tornando pouco razoável o endosso a essa corrente na atualidade. No aspecto político, o populismo é tido como um estilo de política em que o líder se ancora no apoio popular e busca isso sem passar, ou sem depender dos partidos e dos projetos políticos que são vinculados a ele, atribuindo um caráter personalista à política. A fragilidade das instituições representativas poderia justificar o populismo sob esse aspecto político (CARNEIRO, 2009; KNIGHT, 1998; ROBERTS, 2006; SACHS, 1990; WEYLAND, 2001).

Para este trabalho, considera-se importante compreender o populismo enquanto uma estratégia política, cuja finalidade é alcançar o poder e mantê-lo. E destacam-se três características inerentes ao populismo: carisma; discurso antipolítico; e discurso polarizador (CARNEIRO, 2009).

A literatura que trabalha o conceito de populismo sob o aspecto político, também admite os contextos institucional e econômico. Alguns autores, como Roberts (2006), exemplificam isso trazendo o argumento de que o populismo pode 
encontrar um terreno mais fértil em situações de crise econômica. Nesse mesmo contexto, soma-se a incapacidade dos sistemas partidários em estruturar as preferências eleitorais, o que leva o cidadáo a optar por líderes populistas (CARNEIRO, 2009).

O fenômeno do populismo está presente tanto em governos de esquerda quanto nos de direita. Tal fenômeno pode ser explicado pelo nível de confiança que os cidadãos atribuem aos governos democrático-liberais existentes na América Latina, ou seja, especialmente quando a confiança nas instituiçóes políticas é baixa, os eleitores se sentem atraídos pelos candidatos que se dizem radicais outsiders, que vão contra a política vigente (DOYLE, 2011). Na América Latina, o declínio dos partidos vem associado a mudanças de regime. Também se observam lutas entre os partidos, o que, por vezes, ultrapassa o limite da concorrência e da disputa, levando a uma situação de "anulação recíproca" (BAQUERO, 1998).

Doyle (2011) elabora outras hipóteses, além da confiança nas instituições políticas, que podem explicar o apoio eleitoral conquistado pelo populismo em alguns países latino-americanos, tais como: 1) a probabilidade do surgimento do populismo pode ser maior em países com tradição em mobilizaçóes populares; 2) nos países em que houve grande impacto do liberalismo econômico e globalização, os eleitores se sentem mais atraídos por candidatos radicais outsiders que podem vir a solucionar os problemas econômicos do Estado e prover um equilíbrio nos impactos da economia; 3) quanto maiores os índices de inflação de um determinado governo, maiores as chances de o eleitorado apoiar governantes populistas (DOYLE, 2011).

Para tais hipóteses, Doyle (2011) confirmou aspectos importantes: os índices de inflação e o enfraquecimento das instituições partidárias vigentes em determinado país, determinam consideravelmente a eleição de candidatos ditos, pelo autor, como populistas. Mas os índices de mobilização social e dos impactos do liberalismo econômico e da globalização obtiveram números negativos quanto à influência na escolha dos candidatos populistas.

Já para Lanzaro (2007), os novos governos populistas nascem em estruturas nacionais carentes de equilíbrio de poderes e competitividade, com sistemas de partidos fracos ou decomposição (LANZARO, 2007) que trazem consigo líderes com características extremamente personalistas e com um discurso forte da antipolítica. Além disso, os novos governos populistas constroem uma relação intensa líder/massa como estratégia eleitoral. Ainda para o autor, tais governos obtém baixa qualidade democrática por consolidarem um poder muito controlador e, algumas vezes, autoritário. 
Lanzaro (2007) caracteriza o governo de Chávez como um populismo radical com aspirações revolucionárias.

[...] hay uma apelación nacionalista y um ímpetu de ruptura respecto a IV República. El caráter de outsider del presidente pronuncia el quiebre com la política tradional y junto com la distribución de biens públicos, ayuda a construir el liderazgo emergente, que logra um atractivo popular considerable, especialmente entre los sectores marginales y los trabajadores informales ${ }^{1}$ (LANZARO, 2007, p. 8).

A utilização do termo neopopulismo para caracterizar os novos regimes latino-americanos, para Villas (2003), parte de duas premissas básicas: a primeira diz respeito à personalização forte do líder, e a segunda, diz respeito à crise de representação política por que passaram tais governos, o que favorece a eleição dos chamados outsiders. Essas duas características estão fortemente presentes no populismo clássico e, segundo o autor, são retiradas do seu contexto para dar conta de caracterizar os novos governos latino-americanos.

Já segundo Carneiro (2009), cinco características contribuem para classificar governos neopopulistas na América Latina: 1) o forte apelo carismático do líder; 2) a sustentação do discurso antipolítico; 3) o discurso polarizador; 4) a busca de apoio de camadas específicas da sociedade; 5) a recorrência a uma estrutura de mobilizaçáo vertical para chegar ao poder.

A autora levanta, ainda, a hipótese de que os presidentes neopopulistas seriam apoiados por um público que atribui baixa institucionalização ao sistema partidário e que seria, portanto, orientado a uma política personalista. Ou seja, na medida em que a legitimidade no sistema político diminui, aumenta a preferência por líderes personalistas. Os presidentes que compóem esse cenário personificam a preferência desse público, que busca uma liderança inovadora, eficiente no combate à pobreza e que se posiciona contrariamente às instituiçóes "corruptas".

Os baixos índices de confiança nos partidos na Venezuela sugerem uma cultura antipartidária a partir de 1980, como propóe Briceño (2013), favorecendo, então, a busca por alternativas aos partidos, como os líderes neopopulistas. De acordo com Carneiro (2009), na Venezuela, a desconfiança nos partidos políticos chegou a

\footnotetext{
1 “[...] há uma apelação nacionalista e um ímpeto de ruptura em relação à IV República. O caráter de outsider do presidente pronuncia uma quebra com a política tradicional e junto com a distribuição de bens públicos, ajuda a construir o líder emergente, que obtém um apoio popular considerável, especialmente entre os setores marginalizados e os trabalhadores” (LANZARO, 2007, p. 8, tradução nossa).
} 
81\%, em 2004. Os dados do Latinobarômetro (1996 e 2004) para a América Latina reforçam e mostram que, em 2010, o índice de confiança nos partidos não passou de $23 \%$.

O neopopulismo constitui: "as fórmulas políticas cuja fonte principal de inspiração e termo constante de referência é o povo, considerado como agregado social homogêneo e como exclusivo depositário de valores positivos, específicos e permanentes" (BOBBIO, METTEU e PASQUINO, 1998, p. 980).

A partir das cinco características citadas anteriormente: 1) o forte apelo carismático do líder; 2) a sustentaçáo do discurso antipolítico; 3) o discurso polarizador; 4) a busca de apoio de camadas específicas da sociedade; 5) a recorrência a uma estrutura de mobilização vertical para chegar ao poder; e do cruzamento destas com quatro formas de estrutura de mobilizações (partidária, trabalhista, orgânica e eleitoral), Carneiro (2009) elabora um quadro comparativo entre os governos latinoamericanos para classificá-los de acordo com o conceito neopopulista.

Em análise e observação, Carneiro (2009) classificou, então, o governo de Hugo Chávez como um governo extremamente neopopulista, bem como os governos de Evo Morales (presidente da Bolívia), Rafael Correa (presidente do Equador) e Nestor Kirchner (ex-presidente da Argentina). Já Lula (ex-presidente do Brasil) e Calderón (ex-presidente do México) não foram classificados como neopolisistas.

Waisbord (2013) destaca uma importante característica do neopopulismo, salutar a este artigo, que o diferencia do populismo: a relação entre governo e mídia. $\mathrm{O}$ autor menciona que a mídia critica e denuncia problemas dos governos neopopulistas que, por sua vez, procuram cortejar essa mídia, para garantir coberturas favoráveis. É interessante observar que no caso da Venezuela, a saída encontrada foi a privação e o controle da mídia, através das estatizações. O que, em última instância, não zera a atividade das mídias que estão fora do radar do governo, mas insere entraves.

Outro aspecto relevante a ser observado é que essa "pouca liberdade" da mídia venezuelana não descaracteriza o governo de Chávez da proposta de Waisbord (2013), uma vez que o líder neopopulista utiliza a mídia como uma de suas principais estratégias, como veremos adiante.

\section{Imagem pública politica: o populismo de Chávez}

A trajetória política de Chávez leva a uma reflexão sobre o modo como sua construção de herói/messias e líder carismático se deu via crescente e planejado processo de midiatização. 
É possível falar em neopopulismo na Venezuela a partir da segunda vitória de Carlos Andrés Pérez, 1989 (seu primeiro mandato ocorreu entre 1974-1979). "Pérez combinou um estilo populista de discurso e apelo carismáticos com a adoçáo de medidas econômicas neoliberais [...]" (CARNEIRO, 2009, p. 122). O ano de 1992 pode ser considerado como o marco inicial do processo de construção da figura do líder, já que Chávez, a partir da tentativa de golpe de Estado passou a ser um herói nacional um líder bolivariano contra a "corruptocracia" instaurada pelo Pacto de Punto Fijo, integrando um grupo de militares que eram contrários às políticas de Pérez. Em 1993, ele foi acusado de uso indevido do dinheiro público e destituído do cargo.

$\mathrm{Na}$ América Latina, a imagem de Hugo Chávez, em uma escala de 0 a 10, apresenta médias negativas (Quadro 2). Observa-se uma perda de imagem entre os anos de 2005 e 2010, e a sua recuperaçáo ocorre em 2011. Neste ano, no mês de junho, Chávez, em um pronunciamento na TV, anunciou que estava com câncer. Os três países de maior média foram Nicarágua, Venezuela e República Dominicana, 6.3, 6.1 e 5.9, respectivamente. Ao passo que as piores médias foram registradas no Chile, Colômbia e Costa Rica 3.4, 3.4 e 2.4, respectivamente.

Quadro 2 - Hugo Chávez para a América Latina

\begin{tabular}{|c|c|}
\hline Ano & Média \\
\hline 2005 & 5.0 \\
\hline 2006 & 4.6 \\
\hline 2007 & 4.5 \\
\hline 2008 & 4.3 \\
\hline 2009 & 4.2 \\
\hline 2010 & 3.9 \\
\hline 2011 & 4.4 \\
\hline
\end{tabular}

Fonte: Latinobarômetro, $2011^{2}$.

A imagem de Chávez está por todos os cantos do país, desde outdoors que divulgam seus feitos, como exemplo as Missóes, a nomes de escolas que o homenageiam. Quando é eleito em 1998, Hugo Chávez, como bem pontua Oppliger (2010), deixa de ser um ex-líder de um golpe militar fracassado e passa a ser um centro de atenção absoluta em torno do qual giram todos os assuntos da Venezuela.

Segundo Amossy (2008), construir a imagem de si está implícito em todo ato de tomar a palavra. A apresentação de si é efetuada pelo locutor em seu discurso que,

\footnotetext{
${ }^{2}$ A pesquisa foi feita em 19 países da América Latina, entre os anos de 1995 e 2011.
} 
por sua vez, condiciona e facilita o reconhecimento a partir da criação de sua "imagem". Segundo a autora, o termo ethos surge para designar, então, a construção desta imagem de si que é construída para que o discurso obtenha sucesso. Para Barthes, o ethos comporta:

[...] os traços de caráter que o orador deve mostrar ao auditório (pouco importando sua sinceridade) para causar boa impressão: é o seu jeito [...]. O orador anuncia uma informação e ao mesmo tempo diz: sou isto, não sou aquilo (BARTHES apud AMOSSY, 2008, p. 10).

Essa imagem pré-estabelecida ou ethos pré-discursivo pode vir a ser confirmado, reforçado ou reelaborado durante um discurso. De acordo Maingueneau (2008) citado por Amossy (2008, p. 125), nos discursos políticos "os enunciadores que ocupam constantemente a cena midiática são associados a um ethos que cada enunciação pode confirmar ou infirmar".

Sendo assim, segundo a palavra ou o discurso não se tornam mais eficazes somente pelo exterior (ethos institucional) ou pelo interior (ethos discursivo), ambos são complementares (AMOSSY, 2008). É exatamente esta relação entre o ethos institucional e o ethos discursivo que garantem legitimidade ao discurso do orador e podem vir a produzir impressóes favoráveis em seu auditório a partir da interação verbal.

Assim, a figura messiânica e missionária de Chávez (ZÚQUETE, 2008), que se apresenta como o salvador da pátria e do povo, se justifica pela legitimidade discursiva que mandatário traz consigo ao pretender livrar a Venezuela de seus períodos de crise e da burocracia instalada pelo Pacto de Punto Fijo. O "messianismo", do ponto de vista de Legros et al. (2007, p. 219), é "a crença na vinda de um salvador que, depois de um período de fogo e sangue, estabelecerá um reino de paz e de felicidade".

Zúquete (2008) destaca importantes elementos discursivos de Hugo Chávez, que são salutares na construção de sua imagem pública política. Dentre eles destacamos: a figura do líder exemplar; o mártir; o sacrifício; e Chávez do povo.

O messianismo, como explica Negrão (2011), se apresenta de duas formas: a mística e religiosa, que diz de um salvador ou o próprio Deus que é aguardado por todos para instaurar a justiça; e a coletiva e social, que se apresenta "no sentido de concretizar a nova ordem ansiada, sob a condução de um líder de virtudes carismáticas.” (NEGRÃO, 2001, p. 119). Zúquete (2008) também reforça o argumento, na medida em que atribui ao discurso populista. 
Símon Bolívar, ansiado pelo povo venezuelano como o salvador, o grande messias, é substituído pela figura de Chávez nos tempos modernos. A crença do "retorno do messias" é, portanto, agregada à figura de Chávez, que a aceita, e até a reforça, instaurando seu projeto revolucionário de governo e suas ideologias.

Para Marcano e Tyszka (2006), Chávez é um messias que veio do povo, para o povo:

De maneira constante, (Hugo Chávez) recorda sua história, a origem humilde e rural. Não sabe inglês e, publicamente, zomba de sua própria e precária pronúncia. Proclama-se um homem feio, popular, sem propriedades, sem educação para as altas galas, sem outra ambição além do carinho simples e o serviço aos mais necessitados. [...] Chávez é o povo (MARCANO e TYSZKA, 2006, p. 337).

Para alguns autores como Martín-Barbero (2004), esse retorno do messianismo político, traduz um momento pelo qual passa a sociedade e as culturas, momento este que está caracterizado por uma sensação de perda do futuro e estagnação no presente. $\mathrm{O}$ futuro, portanto, é ansiado: espera-se e é desejado que o futuro aconteça não pelas mãos dos homens comuns, mas sim por algo ou alguém de outra parte, um outsider.

Chávez construiu seu discurso estruturado em uma base cultural, exaltando sua identificação com os setores sociais excluídos, na medida em que ele destaca que a enorme crise institucional produziu um progressivo abandono dos cidadáos por parte do Estado. Os eleitores de baixa renda foram "inseridos" no processo eleitoral (JIMÉNEZ, 2006; LUPU, 2010). Interessante observar, nesse sentido, que a entrada de Chávez na cena política como mandatário aumentou o interesse dos venezuelanos pela política (BRICEÑO, 2009).

A figura de Chávez, já presidente, se tornou um fenômeno na Venezuela e sua onipresença no país era nítida. O presidente possuía seu próprio programa televisivo - Aló, presidente! - que ia ao ar todo domingo, com duração mínima de cinco horas. $\mathrm{Na}$ teoria o programa era dominical e durava até cinco horas, mas na prática isso era diferente. Chávez podia colocar o programa no ar no dia que quisesse e no horário que bem entendesse, sem duração máxima. O programa se alimentava da participação popular através de ligaçóes telefônicas, possuía convidados nacionais ou não.

Neste programa Hugo Chávez mantinha contato com os venezuelanos com assuntos diversificados: de esportes à política. Além disso, ele reservava um espaço considerável para agredir a oposição, o imperialismo norte-americano e a imprensa nacional e internacional (quando estas publicam notas que vão contra alguma medida 
de seu governo). Para Krauze (2011, p. 556), essa aproximação com o público gera uma aparência de contato com o poder que é inegável: "a chave principal para a entronização de Chávez não está em suas [...] medidas econômicas ou mesmo no impacto de seus programas sociais, mas em sua manipulação, através da mídia, de sua colossal persona".

Chávez foi o primeiro presidente da Venezuela que nasceu na era da televisão, além disso, sua capacidade de lidar com a comunicação e com o público era inegável. Para Chávez, como bem aponta Oppliger (2010), governar era falar e vice-versa. Segundo o autor, o presidente venezuelano estava constantemente falando, comunicando, explicando, anunciando, ordenando. O mandatário já chegou ao recorde de duração do seu programa Alô, presidente de edição 100, no qual ficou falando por sete horas e meia, em sete de março de 2002. Os números são exorbitantes: "entre febrero de 1999 y junio de 2009, Chávez sumaba 2.810 horas hablando em radio y televisíon, ló que equivale a 351 jornadas laborales de ocho horas: casi um año hablando" (OPLLIGER, 2010, p. 247) ${ }^{3}$. Em abril de 2010, Chávez abriu sua conta no microblog Twitter, desde entáo essa mídia social se tornou mais um dos lugares de fala do mandatário.

A emissora Venezoelana de Televisión, a VTV, se transformou em um dos instrumentos comunicacionais mais importantes do governo chavista. Responsável pela transmissão do Alô, presidente, a emissora acompanhou todos os passos da midiatização de Chávez e corroborou para a construção da sua imagem pública.

O advento da chamada "conversação-espetáculo" alterou drasticamente o discurso político midiatizado. Sob a égide de uma democracia da expressão passa-se a "ver o homem privado sob o personagem público" (COURTINE, 2003, p. 24). A politica da vida privada exibe intimidades e a política se vê banalizada nas vidas cotidianas. O que bem salienta Marcano e Tyszka (2006) é que a pessoa pública e a pessoa privada de Hugo Chávez eram a mesma figura, a população venezuelana já não conseguia fazer distinção entre uma e outra.

Eco (2012, p. 23) ressalta, ainda, a alteraçáo significativa que o carisma dos presidentes e a consequente midiatização presidencial proporcionaram: "Se me perguntassem há vinte anos, eu não saberia dizer quem era o presidente da Venezuela, quem era o presidente do Peru, ou o presidente da Argentina. Agora eu posso".

\footnotetext{
3 “[...] entre fevereiro de 1999 e junho de 2009, Chávez somava 2.810 horas falando em rádio e televisão, o que se equivale a 351 jornadas de trabalho de oito horas: quase um ano falando" (OPLLIGER, 2010, p. 247, tradução nossa).
} 
Em seus programas de rádio, TV, bem como no Twitter, Chávez já tomou decisóes importantes do Executivo: demitiu funcionários públicos, voltou atrás em decisóes econômicas, mandou cortar gastos públicos, anunciou medidas importantes, entre outros. Ou seja, governou boa parte do seu período no poder através dos meios de comunicação. Essas atitudes do presidente geram implicações drásticas da via governamental:

[...] muchas de esas decisiones son tomadas in situ, sin haber sido consultadas por otras instancias - técnicas o políticas - del gobierno. En el fondo, la improvisación es una característica esencial de la gestión bolivariana. Una improvisación que se origina en el Ejecutivo, pero que irradia inmediatamente al resto de los poderes públicos y al aparato estatal (OPLLIGER, 2010, p. 248) ${ }^{4}$.

Fausto Neto, Mouchon e Verón (2012) e Krauze (2011) apontam para o fato de que essa midiatização exacerbada do presidente Chávez leva a questão dos aspectos institucionais e não institucionais do funcionamento da política, ou seja, o presidente - midiatizado - teria condições de tomar decisóes não institucionais, ou que escapam às instituições, como é o caso específico de Chávez na Televisão e no Twitter ao tomar várias decisóes do Executivo nos meios de comunicação.

A ação política de Chávez estava representada na e por meio da mídia. A interação de Chávez com a população venezuelana, bem como a consolidação de sua imagem pública no âmbito internacional realizada por meio das redes de informações, não era mais identificada com as primeiras interações televisivas, mas já estava marcada pelas tomadas de decisóes ao vivo, mascaradas pelo ato conversacional que o mandatário permanentemente realizava nos meios de comunicaçáo.

\section{A escolha pelo continuismo}

Briceño (2013) salienta que a crise dos partidos políticos do fim da década de 1970 foi uma consequência de um processo mais amplo: do desencanto político. $\mathrm{Na}$ sequência, assistiu-se ao surgimento de novos atores políticos que atenderiam à demanda de substituição dos partidos políticos; em 1993, Rafael Caldera chegou ao poder e depois o outsider Hugo Chávez, com o Movimiento V República (MVR). "O

\footnotetext{
4 “[...] muitas dessas decisões são tomadas in situ, sem serem consultadas ou avaliadas por outras instâncias - técnicas ou políticas - do governo. No fundo, a improvisação é uma característica essencial da gestão bolivariana. Uma improvisação que se origina no Executivo, mas que interfere necessariamente em outros poderes públicos e no aparato estatal” (OPLLIGER, 2010, p. 248, tradução nossa)
} 
colapso do sistema de partidos e sua dispersão seguem sendo a manifestação mais importante das mudanças no comportamento eleitoral venezuelano" (BRICEÑO, 2013, p. 32). Destaca-se, nesse contexto, a diminuição da importância dos fatores institucionais-estruturais que cederam lugar aos conjunturais políticos.

Entre os anos de 1958 e 1998, a Venezuela vivia sob um regime democrático que foi marcado pela corrupçáo, pelo clientelismo político e por uma situação de apatia política (OLIVEIRA, 2011). O país que vinha consolidando um sistema bipartidário começou a viver uma situação de crescente erosão da confiança nos partidos tradicionais o que culminaria, em 1998, em fortes mudanças na participação eleitoral e na formação de novas lealdades partidária (BRICEÑO, 2013). A deslegitimação partidária e do próprio sistema político, visível a partir das eleições de 1989 (regionais e locais) e mais destacada nas nacionais de 1993 (parlamentares e presidenciais), levou a um período de grande fragmentação partidária que, até os dias de hoje, conforme pontua Briceño (2013), continua sem solução.

A ascensão de Hugo Chávez marcou um período de grande mobilização política e de um retorno a uma sociedade mais politizada, e de aliança cívico-militar que favoreceu o fortalecimento do regime e, ainda, promoveu resistência à "dominação" norte americana. Chávez retomou a ideia de "Revolução pacífica", como a registrada entre 1970 e 1973 no Chile.

A partir de dados do IPSOS Latin America Pulse, Carneiro (2009) constatou que na sua última reeleição a aprovação de Chávez atingia 67,8\% e o apoio ao governo chegava aos $65,2 \%$. Acrescentando variáveis do Latinobarômetro (1996 e 2004), a autora também constatou que $80 \%$ não confiavam em partidos e $50 \%$ acreditavam que pode haver democracia sem o Congresso Nacional. Os dados "sugerem que existe uma tendência generalizada de apoio do público latinoamericano a uma democracia 'desinstitucionalizada', na qual o papel dos partidos como instituiçóes mediadoras do poder público tem pouca importância” (CARNEIRO, 2009, p. 132).

Chávez disputava a reeleição e, portanto, procurou enfatizar a importância da continuidade de seu governo para o país (MACHADO, 2009), buscando, também, o voto retrospectivo. E tal compreensão do processo é ancorada na visão de outros autores, como Baquero e Linhares (2011), que concordam que os resultados eleitorais na América Latina têm se mostrado próximos não apenas das hipóteses do voto personalista, mas também, do voto retrospectivo.

Lupu (2010), buscando alternativas que expliquem o comportamento do eleitor chavista, investigou as eleiçôes de 1993 a 2006, observando o efeito da renda familiar na decisão do voto. $\mathrm{O}$ autor explica que a literatura comumente aborda que o 
sucesso eleitoral de líderes como Chávez depende, sobretudo, do voto de classe; especialmente do apoio de eleitores de classes mais baixas e que estão desencantados com a política. Porém, a pesquisa de Lupu (2010) sugere que o voto de classe na Venezuela não segue a descrição da maioria dos autores, para os quais os eleitores mais ricos são os menos propensos a votar em Chávez; segundo ele, em 1998 surgiu um voto multiclasse. A retórica de Hugo Chávez se manteve - nacionalista, antioligárquico e visando as classes baixas - e, ao mesmo tempo, ele atraiu os eleitores de classe média, com propostas de políticas de desenvolvimento redistributivas e estadistas mais amplas que beneficiariam esses setores.

\section{As eleições presidenciais de 2012 na Venezuela}

As eleiçóes presidenciais de 2012 na Venezuela são um importante fator a ser analisado em relação à existência da estratégica neopopulista relacionada ao governo de Hugo Chávez. As fontes utilizadas para coleta de informaçóes das campanhas eleitorais de ambos os candidatos à eleição (Chávez e Henrique Capriles) foram jornais online bem como discursos proferidos pelos dois candidatos em sítios oficiais na Internet. Para consecuçáo da análise do material coletado foi utilizado o método de análise de conteúdo.

Em eleiçôes primárias inéditas na Venezuela, realizadas no dia 12 de fevereiro de 2012, a oposição escolheu o candidato que disputou as eleiçóes presidenciais com Chávez, em 07 de outubro deste mesmo ano. As primárias foram disputadas pelos dois principais candidatos da oposição, o governador do estado de Miranda - o segundo mais populoso do país - Henrique Capriles e Pablo Pérez, ex-governador do estado de Zulia; a deputada María Corina Machado, o ex-embaixador Diego Arria e o sindicalista Pablo Medina. Com participação de 2,9 milhóes de eleitores, mais do que o esperado, Henrique Capriles, de 39 anos, do partido Primeiro Justiça, venceu as primárias com $62 \%$ dos votos válidos.

Segundo Dieguez (2012), o quadro de disputa entre Chávez e Capriles foi intenso, pesquisas realizadas sobre as intençôes de voto variavam entre seis a vinte pontos de diferença entre os candidatos, sempre a favor de Chávez. Há vários institutos de pesquisa eleitoral na Venezuela, portanto, há inúmeras divergências quanto aos números das intenções de voto. De acordo com o Datanálisis (2012), em maio de 2012, as intençóes de voto para Chávez eram de $44 \%$ enquanto para Capriles eram de 31\%. Em pesquisa datada de 22 de julho de 2012, realizada pelo Instituto Venezuelano de Análises de Dados (IVAD) Chávez manteve a preferência dos votos com $52,3 \%$ das intenções, já Capriles possuía 32\%. 
As eleições presidenciais eram um enigma para o povo venezuelano, muito em função da doença de Chávez e das especulações quanto a sua capacidade de concorrer efetivamente em outubro. As especulações em torno das reais condições de Chávez e a audiência que essas questôes têm na Venezuela poderia prejudicar a campanha de Capriles, já que não sobrava muito espaço para que o candidato oposicionista divulgasse suas ideias (DIEGUEZ, 2012). O que Capriles fez durante sua campanha foi visitar todas as comunidades da Venezuela. De acordo com o candidato, a campanha "corpo a corpo" é a que mais podia aproximá-lo de seus eleitores.

O slogan da campanha de Capriles era "Hay um Camino!" ("Há um Caminho!"), em biografia disponível no site oficial, podia-se perceber os compromissos que Capriles assumia com seus eleitores:

El 12 de Febrero, gracias al voto y la confianza de los ciudadanos, Henrique Capriles Randonski obtuvo el respaldo de casi dos millones de venezolanos que dijeron ¡Sí Hay un Camino! [...] El compromiso se mantiene: luchar para que todos tengan una vida mejor, sin importar de dónde vengan o a cuál partido político apoyan. [...] Esa seguirá siendo su prioridad como Presidente de Venezuela: oportunidades para todos por igual $^{5}$ (BIOGRAFÍA, 2012).

Capriles enfrentou uma população acostumada a 14 anos de assistência social que Chávez investiu no país. O candidato da oposição possuía uma imagem bem diferente de Hugo Chávez e, como aponta Dieguez (2012), representava o que os pobres mais rejeitavam: era branco, fazia parte da elite, e era ligado aos partidos tradicionais antes tão contestados.

Era grande o desafio de enfrentar a imagem consolidada de Chávez no país. Em pesquisa realizada pelo Datanálisis, em maio de $2012^{6}, 50,5 \%$ dos entrevistados afirmaram confiar em Chávez e $62,4 \%$ aprovavam seu trabalho no governo (DATANÁLISIS, 2012). O mesmo instituto realizou uma pesquisa de intenção de voto, em junho de $2012^{7}$, na qual Chávez alcançou $46,1 \%$, contra $30,8 \%$ de Capriles

\footnotetext{
5 "Em 12 de fevereiro, graças ao voto e a confiança dos cidadãos, Henrique Capriles Randoski obteve o respaldo de quase dois milhões de venezuelanos, que disseram "Sim, Há um Caminho!". O compromisso se manteve: lutar para que todos tenham uma vida melhor, sem importar de onde vêm e qual partido político apoiam. Essa seguirá sendo a sua prioridade como Presidente da Venezuela: oportunidades iguais para todos" (BIOGRAFÍA, 2012, tradução nossa).

${ }^{6}$ Pesquisa realizada entre os dias 21 e 29 de maio de 2012, com 1300 entrevistas. Margem de erro de $2,72 \%$.

${ }^{7}$ Pesquisa realizada entre os dias 14 e 23 de junho de 2012, com 1300 entrevistas. Margem de erro de $2,72 \%$.
} 
(CHÁVEZ, 2012). Ainda segundo Dieguez (2012), Capriles encabeçava um jogo de forças importante contra Chávez em um movimento que ficou conhecido como Tococha (Todos Contra Chávez).

Chávez oficializou sua candidatura em 11 de junho de 2012, um dia depois de Capriles e no último dia previsto em lei para lançamento das candidaturas. Desde fevereiro de 2012, Chávez não se apresentava em comícios, neste dia 11 de junho reuniu militantes e simpatizantes de seu governo em frente à sede do Conselho Nacional Eleitoral da Venezuela. De boina vermelha e vestindo trajes com as cores da bandeira nacional, Chávez discursou por quase três horas e demonstrou vigor e saúde, contrariando opinióes de que, devido ao câncer, não poderia se candidatar.

Importante salientar o aspecto das características específicas de uma reeleição, como era o caso de Chávez. O discurso a favor da continuidade da gestão administrativa, o lugar de autoridade do candidato-Presidente e a ênfase em discurso programático de cunho econômico são características importantes adotadas pelo mandatário para definir o campo do embate político entre os candidatos. (MACHADO, 2009).

A campanha de Chávez em 2012 teve como slogan: "Chávez, corazón de mi pátria" (Chávez, coração de minha pátria), o que ratificava o tom nacionalista do discurso chavista. João Santana, responsável pela campanha de Lula à reeleição no Brasil em 2006 e pela campanha de Dilma Rousseff em 2010, foi o responsável pela campanha de Hugo Chávez em 2012. A campanha de Capriles também foi dirigida por dois brasileiros, Renato Pereira e Chico Mendez.

O Plano de Governo (2013-2019) ${ }^{8}$, apresentado por Chávez em 11 de junho de 2012, trazia os seguintes objetivos principais, segundo site oficial da campanha:

a) Defender, expandir e consolidar o bem mais precioso que reconquistamos depois de 200 anos: a independência nacional;

b) Continuar construindo o Socialismo Bolivariano do século XXI na Venezuela, como alternativa ao modelo selvagem do capitalismo e com isso assegurar uma "maior segurança nacional, maior estabilidade política e mais felicidade”, para nosso povo;

c) Converter a Venezuela em uma potência social, econômica e política dentro da grande potência emergente da América Latina e Caribe, que garantiria uma conformação de uma zona de paz em nossa América;

\footnotetext{
8 Versão completa do Plano de Governo (2013-2019) de Hugo Chávez. Disponível em: <http://static.eluniversal.com/2012/06/12/proyecto2013-2019.pdf>. Acesso em: 11 de março de 2014.
} 
d) Contribuir para o desenvolvimento de uma nova geopolítica internacional na qual se concretize o mundo multicêntrico e pluripolar que permita alcançar o equilíbrio do universo e garantir a paz planetária;

e) Contribuir com a preservação da vida no planeta e a salvação da espécie humana.

A campanha eleitoral teve início oficialmente em $1^{\circ}$ de julho de 2012 , além da campanha nas ruas, os candidatos tiveram espaços em todos os meios de comunicação, com ênfase para o horário político eleitoral na TV e também a Internet. Ainda no primeiro dia, foi lançado um vídeo da abertura oficial da campanha de Chávez que contava com um apelo emocional característicos das campanhas de João Santana e já muito conhecido pelos brasileiros nas campanhas de Lula da Silva e Dilma Rousseff. Com o título "Soy Chávez de corazón - Vamos tod@s juntos hasta la victoria del 7-O" (Sou Chávez de coração - Vamos todos juntos à vitória de 7 de outubro), o vídeo apresentava imagens do povo venezuelano exaltando Chávez com o grito de "Uh! Ah! Chávez não se vá!".

Chávez venceu as eleições com 55,07\% dos votos válidos contra 44,31\% de Capriles, como indica o Quadro 3 abaixo:

Quadro 3 - Possibilidade de reeleição presidencial

\begin{tabular}{|c|c|c|}
\hline Candidato & Votos & \% \\
\hline Hugo Chávez & 8.191 .132 & 55,07 \\
\hline Henrique Capriles & 6.591 .304 & 44,31 \\
\hline
\end{tabular}

Fonte: Divulgación Elección Presidencial - Comissão Eleitoral Nacional da Venezuela.

Essa vitória garantiria que o governo de Chávez permanecesse na presidência até 2019, o que somaria 20 anos no poder, mas Chávez faleceu em março de 2013 e quem o sucedeu na presidência, com novas eleições presidenciais, foi Nicolás Maduro, companheiro de partido de Chávez que prometeu continuar o legado chavista na Venezuela.

\section{Considerações finais}

A América Latina passa por um processo de reestruturação de sua democracia, em busca de sua consolidação, especialmente sob o aspecto institucional. Porém, os laços entre o Estado e a sociedade, intermediados pelos partidos políticos, não têm se mantido estáveis e eficientes. Vários fatores contribuem para essa situação, sendo agravados por instabilidade econômica ou do próprio sistema político. E o resultado é o sentimento de desconfiança na política, sobretudo nos partidos políticos, colocando 
em xeque as suas capacidades enquanto instância mediadora entre o Estado e a sociedade.

Diversas hipóteses buscam compreender e explicar o personalismo político e, por conseguinte, o populismo. Acredita-se que a crise de representatividade, a desconfiança nas instituiçóes representativas, acompanhada pelo desinteresse por política favorecem o surgimento de líderes personalistas.

Nesta oportunidade, voltou-se o olhar à Venezuela buscando compreender o cenário de disputa presidencial de 2012, a partir do discurso do populismo. E partindo da premissa de que o populismo é também uma estratégia de campanha, o presente trabalho analisou o discurso político de Chávez e observou a construção da imagem do líder populista. Também é relevante observar a proximidade entre Hugo Chávez e o neopopulismo, sobretudo, no que se refere à relação entre governo e mídia. Mais ainda, a utilizaçáo da mídia enquanto componente estratégico da construção e reforço da imagem de Chávez enquanto um líder (neo)populista, a partir de seu discurso político.

Observou-se, ainda, que muitos estudiosos buscam explicaçóes para o voto chavista, de modo que, além da hipótese do voto personalista, também se investiga sobre o voto retrospectivo (BAQUERO e LINHARES, 2011), baseado na recompensa por um bom governo. Trata-se, também, do voto multiclasse, ou seja, Chávez teria conseguido, a partir das eleições de 1998, mobilizar não apenas as classes mais baixas, mas também setores da classe média (LUPU, 2010).

$\mathrm{Na}$ América Latina, de modo geral, o sistema partidário ainda é consideravelmente fragmentado e a identificação partidária é baixa. O que se percebe é um crescente número de eleitores sem identificação partidária e, também, o surgimento de novos atores políticos que trazem novas propostas para suprir as demandas dos cidadãos que não são atendidas pelos partidos, o que passa a ser pretexto para o surgimento do personalismo político.

Érica Anita Baptista é Pesquisadora do grupo "Opinião Pública, Marketing Politico e Comportamento Eleitoral" da Universidade Federal de Minas Gerais (UFMG) e Doutoranda em Ciência Politica na UFMG. E-mail: anitaerica@gmail.com

Mariana Rezende dos Passos é Pesquisadora do "Grupo de Estudos de Novas Narrativas" e Doutoranda em Comunicação Social na Universidade de São Paulo. E-mail: maryrpassos@gmail.com 


\section{Referências}

AMOSSY, Ruth (Org.). Imagens de si no discurso: a construção do ethos. São Paulo: Contexto, 2008.

BAQUERO, Marcello. Identificação partidária e comportamento eleitoral. In: $22^{\circ}$ Encontro Anual da ANPOCS, Caxambu, 1998.

BAQUERO, Marcello; LINHARES, Bianca de F. Por que os brasileiros não confiam nos partidos? Bases para compreender a cultura política (anti)partidária de possíveis saídas. Revista Debates, v. 5, n. 1, 2011.

BIOGRAFÍA. Hay un Camino. Publicado em: 7 de dez. de 2012. Disponível em: < http://hayuncamino.com/biografia/> Acesso em: 12 out. 2013.

BOOBIO, Noberto; MATTEUCCI, Nicola; PASQUINO, Gianfranco. Dicionário de política. Brasília: Editora Universidade de Brasília, 1998.

BRICEÑO, Hector. Mudanças no comportamento eleitoral e no sistema de partidos na Venezuela (1958-2010). In: TELLES, Helcimara; MORENO, Alejandro (Orgs.). Comunicação Política e Comportamento Eleitoral na América Latina. Belo Horizonte: Editora UFMG, 2013.

BRICEÑO, Hector. Participación electoral y cultura política en Venezuela (1958-2007). Cuadernos del Cendes, n. 72, p. 37- 65, 2009.

CAMPBELL, Angus et al. The american voter. New York: John Wiley, 1960.

CARNEIRO, Gabriela O. P. A Nova Maioria: Determinantes do Apoio Político ao Neopopulismo na América Latina. 2009. 157f. Tese (Doutorado em Ciência Política) - Programa de Pós-graduação em Ciência Política, Universidade de São Paulo, São Paulo, 2009.

CHÁVEZ mantém liderança sobre Capriles em pesquisa eleitoral. Agência Reuters, 16 jul. 2012. Disponível em: <http://br.reuters.com/article/idBRSPE86F03E20120716>. Acesso em: 11 mar. 2014.

CHERESKY, Isidoro (Orgs.). Elecciones presidenciales y giro politico en América Latina. Buenos Aires: Manantial, 2007.

COURTINE, Jean-Jacques. Os deslizamentos do espetáculo político. In. GREGOLIN, Maria do Rosário (Org.) Discurso e mídia: a cultura do espetáculo. São Carlos: Claraluz, 2003.

DATANÁLISIS revela que aumenta brecha electoral a favor de Chávez. Agência Venezoelana de Noticias, 25 jun. 2012. Disponível em: <http://www.avn.info.ve/contenido/ datan\%C3\%A1lisisrevela-que-aumenta-brecha-favor-candidatura-ch\%C3\%A1vez>. Acesso em: 29 out. 2013.

DIEGUEZ, Consuelo. O candidato Tococha: Lula inspira Henrique Caprilles, o homem que vai enfrentar Chávez nas urnas da Venezuela. Revista Piauí, n. 69, p. 38-47, jun. 2012.

DOYLE, David. The Legitimacy of Political Institutions: Explaining Contemporary Populism in Latin America. Comparative Political Studies, v. 20, n. 10, p. 1-27, 2011.

DOWNS, Anthony. An economic theory of democracy. New York: Harper and Row, 1957.

ECO, Umberto. Entrevista Umberto Eco. In: FAUSTO NETO, Antônio; MOUCHON, Jean; VERÓN, Eliseo (Orgs.). Transformaçôes da midiatização presidencial: corpos, relatos, negociaçóes, resistências. São Caetano do Sul, SP: Difusão Editora, 2012. p. 15-26. Entrevista concedida a Eliseo Verón.

FAUSTO NETO, Antônio; MOUCHON, Jean; VERÓN, Eliseo (Orgs.). Transformaçōes da midiatização presidencial: corpos, relatos, negociaçôes, resistências. São Caetano do Sul, SP: Difusão Editora, 2012.

FIGUEIREDO, Marcus; ALDE, Alessandra. Intenção de voto e propaganda política: efeitos e gramáticas da propaganda eleitoral. In: 12 Encontro Anual da Compós, Recife, 3-6 jun. 2003. 
FIGUEIREDO, Marcus. A Decisão do Voto: democracia e racionalidade. São Paulo: Ed. Sumaré, 1991.

GARRETÓN, Manuel Antonio. Elecciones presidenciales e nueva problemática histórica. In: CHERESKY, Isidoro (Org.). Elecciones presidenciales y giro politico en América Latina. Buenos Aires: Manantial, 2007.

GERMANI, Gino. Authoritarianism, fascism, and national populism. New Brunswick, NJ: Transaction Books, 1981.

JIMENES, Juan Eduardo. Algunas claves para entender el discurso político de Hugo Chaves (1998 - 2004). RIPS - Revista de Investigación Política y Sociológica, v. 5, n. 1. p. 199-214, 2006.

KNIGHT, Alan. Populism and Neo-Populism in Latin America, especially Mexico. Journal of Latin American Studies, v. 30, n. 2, p. 223-48, 1998.

KRAUZE, Enrique. Os redentores: ideias e poder na América Latina. Tradução de Magda Lopes, Cecília Gouvêa Dourado e Gabriel Federicci. São Paulo: Saraiva, 2011.

LACLAU, Ernesto. Politica e ideología en la teoría Marxista: Capitalismo, fascismo, populismo. Londres: Verso, 1980.

LANZARO, Jorge. Gobiernos de izquierda en América Latina: entre el populismo y la social democracia - una tipologia para avanzar em el análisis comparado. Análise de Conjuntura OPSA, n. 12, dez. 2007.

LAZARSFELD, Paul; BERELSON, Bernard; GAUDET, Hazel. The people's choice: how the voter makes up his mind in a presidential campaign. New York: Columbia University Press, 1965.

LATINOBARÔMETRO. Las imágenes de Hugo Chaves (1995 - 2011). 2011.

LEGROS, Patrick et al. Sociologia do imaginário. Porto Alegre: Sulina, 2007.

LUPU, Noam. Who Votes for Chavismo? Class Voting in Hugo Chávez's Venezuela. Latin American Research Review, v. 45, n. 1, p. 24-25, 2010.

MACHADO, Mônica. A retórica da reeleição: mapeando os discursos dos Programas Eleitorais (HGPE) em 1998 e 2006. Opinião Pública, v. 15, n. 1, p. 159-189, jun. 2009.

MÄDER, Maria Elisa Noronha de Sá. Perspectivas para a América latina no século XXI. Revista História Agora, Rio de Janeiro, v. 1, p. 1-7, 2007.

MAINGUENEAU, Dominique. Ethos, cenografia e incorporação. In: AMOSSY, Ruth. Imagens de si no discurso: a construção do ethos. São Paulo: Contexto, 2008. p. 69-92.

MARCANO, Cristina; TYSZKA, Alberto Barrera. Hugo Chávez sem uniforme: uma história pessoal. Tradução de Marcos Santarrita. Rio de Janeiro: Gryphus, 2006.

MARTÍN-BARBERO, Jesus. Razón técnica y razón política: espacios/tiempos no pensados. Revista Latinoamericana de Comunicación (ALAIC), n. 1, p. 22-37, 2004.

MITRE, Antônio. As peregrinaçôes de um conceito: populismo na América Latina. Cadernos de História, v. 10, n. 13, p. 9-23, $1^{\circ}$ sem. 2008.

NEGRÃO, Lísias Nogueira. Revisitando o messianismo no Brasil e profetizando seu futuro. RBCS, v. 16, n. 46, jun. 2001.

OLIVEIRA, Renata P. Velhos fundamentos, novas estratégias? Petróleo, Democracia e a Política Externa de Hugo Chávez (1999-2010). 2011. 182f. Tese (Doutorado em Ciência Política) - Programa de Pós-graduação em Ciência Política, Universidade Federal de Minas Gerais, Belo Horizonte, 2011.

OPPLIGER, Marcel. La revolución fallida: un viaje a La Venezuela de Hugo Chávez. Santiago: Instituto Democracia y Mercado, 2010. 
ROBERTS, Kenneth M. Populism, Political Conflict and Grass-Roots Organization in Latin America: A Comparison of Fujimori and Chavez. Comparative Politics, v. 38, n. 2, p. 127-48, 2006.

SÁEZ, Manuel A. FREIDENBERG, Flavia. Partidos políticos na América Latina. Opinião Pública, Campinas, v. VIII, n. 2, 2002, p. 137-157.

SACHS, Jeffrey Y. Social Conflict and Populist Politics in Latin America. San Francisco: ICS Press, 1990.

SAISI, Kátia. Campanhas presidenciais na América Latina: convergências e divergências no discurso midiático. 2011. 392f. Tese (Doutorado em Ciências Sociais) - Programa de Pós-graduação em Ciências Sociais, Pontifícia Universidade Católica de São Paulo, São Paulo, 2011.

TELLES, Helcimara. O "fator Lula" nas presidenciais de 2010: Atalho cognitivo, voto heurístico e confiança $2012 . \quad$ política. 2 Disponível $<$ http://portal.anpocs.org/portal/index.php?option=com_docman\&task=doc_view\&gid=7842\&Ite mid=76>. Acesso em: 11 mar. 2014.

TORRE, Carlos de la. The ambiguous meanings of Latin American populisms. Social Research, v. 2, n. 59, p. 385-414, 1992.

VILAS, Carlos M. Populismos reciclados o neoliberalismo a secas? El mito Del "neopopulismo" latinoamericano. Revista Venezoelana de Economia y Ciencias Sociales, Venezuela, v. 9, n. 3, p. 1336, 2003.

WAISBORD, Sílvio. Populismo e mí dia: o Neopopulismo na Amé rica Latina. Tradução de Juliana Glagiardi. Contracampo, v. 28, n. 3, p. 26-51, dez. 2013.

WEFFORT, Francisco C. O Populismo na Política Brasileira. 5a ed. Rio de Janeiro: Paz e Terra, 2003.

WEYLAND, Kurt. Clarifying a Contested Concept: Populism in the Study of Latin American Politics. Comparative Politics, v. 34, n. 1, p. 1-22, 2001.

ZÚQUETE, João P. The Missionary Politics of Hugo Chávez. Latin American Politics and Society, v. 50, n. 1, p. 91-121, 2008.

Texto recebido em 15 de dezembro de 2013. Aprovado em 07 de março de 2014. 
